\title{
COMMENT
}

\section{December ECI biocommentary}

\author{
Kristin Keunen ${ }^{1}$ \\ Pediatric Research (2018) 84:790; https://doi.org/10.1038/s41390-018-0193-7
}

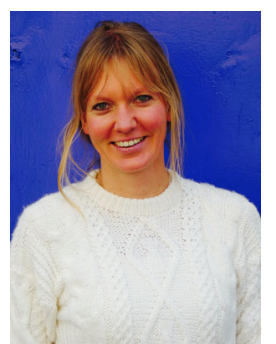

I grew up in a small town in the Netherlands, where my grandfather would take me for long bike rides on the countryside. He encouraged me to always wonder why, sparking my curiosity. At age 18 , I was ready to move to the city, and went to medical school at Utrecht University. My first research experience was in pediatric gastroenterology but it was not until a lecture about embryonic brain development that I truly became a research enthusiast. I wanted to learn everything there was to know about early brain development. As a little girl, age 18 months I had been admitted to a hospital for 6 months, which fed into my ambition to care for children and promote healthy development.

In 2011, I got the opportunity to do a research internship at Brigham and Women's hospital, Harvard Medical School in Boston with Prof. Amir Lahav. This turned out to be the stepping-stone for my PhD in neonatal brain development at the University Medical Center Utrecht (UMCU) supervised by Prof. Manon Benders and Prof. Linda de Vries; two ambitious, talented, and caring women who have been the most significant mentors in my career to date.
From 2014, I started spending time at the Dutch Connectome Lab to learn connectivity analysis supervised by Dr. Martijn van den Heuvel. He taught me to think out of the box, be the leader of a research project and stimulated my creativity. Other role models that have been key inspirators along the way include Prof. Moriah Thomason (Wayne State University) who has strong female leadership and a pioneering line of research, and Prof. Edward Nieuwenhuis (UMCU) who has challenged me to stay true to myself and have the courage to follow my dreams. I have recently started residency in anesthesiology, aiming to become a pediatric anesthetist-intensivist and combine clinical work with a scientific career.

I think one of the most important qualities a good scientist has is critical thinking. Therefore, I would like to advice young researchers to ask questions, be self-critical and critical toward the information provided to them. Work hard, but make sure you find a balance between work, family, friends, and things you like to do for yourself. Never compromise your values. Believe in yourself and do not let anyone make you believe that you cannot do something. If you fail, try again. If it is what you really want in your heart, the universe will ultimately conspire to make it happen.

\section{ADDITIONAL INFORMATION}

Competing interests: The authors declare no competing interests.

Publisher's note: Springer Nature remains neutral with regard to jurisdictional claims in published maps and institutional affiliations. 